\title{
Laughter and Smiling in 16 Positive Emotions
}

\author{
Jennifer Hofmann, Tracey Platt and Willibald Ruch
}

\begin{abstract}
This study investigated the elicitation of smiling and laughter and the role of facial display regulation markers (e.g., down-regulating of a smile or laugh) in positive emotions. In a structured group conversation setting, the frequency and intensity of Duchenne and non-Duchenne smiles and laughs when telling memories of 16 positive emotions proposed by Ekman [1] were assessed. Facial responses were coded with the Facial Action Coding System (FACS [2]) and laughter vocalizations were assessed. The results show that smiles and laughs occurred in all 16 positive emotions. Laughter occurred most often in amusement and schadenfreude (laughter occurred in $72 \%$ and $71 \%$ of the recalled emotion memories respectively). Also, the intensity of the smiles and laughs was higher in amusement and schadenfreude than in the other 14 positive emotions. Furthermore, down-regulated displays (i.e., including facial markers counteracting the upward action of the zygomatic major muscle) resembled Duchenne Displays in their intensity. To summarize, more insight is gained into the facial expression of positive emotions, also highlighting the role of laughter. Also, the importance of assessing regulation markers in joy displays when people are in social settings is stressed.
\end{abstract}

Keywords - Facial Action Coding System, Facial Expression, Emotion Recall, Laughter, Positive Emotions, Smiling

\section{INTRODUCTION}

\subsection{LaUghter and Smiling in Positive Emotions}

SMILING and laughter are claimed to be universal Sindicators of joy [3][4][5][6][7]. Still, little is known about the expression of smiling and laughter in facets of joy (i.e., positive emotions). Only a few studies have been conducted on smiling [8], and even less is known about the occurrence of laughter in positive emotions. In the current approach, the occurrence of smiling and laughter in a broad list of positive emotions was of interest. Emotions were induced by an emotion recall technique, embedded in a social situation (recalling emotions in a structured group conversation task). The frequency and intensity of smiling and laughter (as well as facial markers of expression regulation) were assessed by coding facial actions and laughter vocalizations of the individuals telling memories of their emotion events to a group.

With respect to facial expressions, the experience of joy in general and some facets of positive emotions in particular were linked to the expression of the Duchenne Display (DD; the joint and symmetric contraction of the zygomatic major and orbicularis oculi pars orbitalis muscles [9]). Although the DD has also been found to occur in nonjoyful and social situations [10], as well as in posed expressions [11] [12], the DD is still distinguishable from other smiles and laughs 1 and correlates with self-ratings of positive experience (i.e., joy; the perceived funniness of jokes correlates with DD laughter 2 [9][11][13][14][15] [16][17][18][19][20]. Based on predictions from componential emotion models, Scherer and Ellgring [21][22] postulated that enjoyment/happiness and elation/joy

- J. Hofmann is with the Department of Psychology at the University of Zurich, Switzerland, Binzmuhlestrasse 14, Box 7, CH-8050 Zurich. Email: j.hofmann@psychologie.uzh.ch

- T. Platt is with the Department of Psychology at the University of Wolverhampton, United Kingdom. E-mail: T.Platt@wlv.ac.uk.

- W. Ruch is with the Department of Psychology at the University of Zurich Switzerland, E-mail: w.ruch@psychologie.uzh.ch activate the zygomatic major muscle, the orbicularis oculi pars orbitalis muscle (both DD markers), plus upper lid raising, lips parting and jaw dropping, lip corner depressing, as well as forehead frowning in the latter case. The actions can be combined in a dynamic fashion [21] [22].

While positive emotions may all elicit smiles and laughs, these displays might differ in their frequency, intensity of the displays, temporal features, the cooccurrence of laughter, posture changes, gaze, or vocalizations, or involvement of further facial actions (see [1] [8] [7] [21] [22] [23] [24]). So far, studies on the expressive patterns of positive emotions were often limited to either a small set of emotions, and/or are specific to one modality (i.e., facial features or vocalizations; for a review see [7]). For example, [25] claimed that sensory pleasures, mirth, happiness, and joy are expressed by smiling. In posing studies, awe, pride and amusement contained a smile in $56-85 \%$ of the expressions (see [26]). More recently, [35] investigated the expressive patterns of eight positive emotions and found distinct (posed) expressions for amusement, awe, interest, joy, love, contentment, and pride, but not gratitude. Likewise, specific facial smiling patterns were found for interest, pleasure, pride and joy in decoding studies [8].

1 Differences between DD and non-DD smiles were found in intensity [11]; symmetry and dynamics, for example asymmetry of amplitude, onset and offset velocity, smile controls [12][27][28], speed and acceleration [95], duration, as well as coincidence of the smile with speech and motoric behavior [9][29], i.e., accompanying head and shoulder movements [97]. Moreover, [96] found an effect of age on smiling dynamics. Evidence is mixed on whether the AU6 can serve as a "reliable" muscle which is an inevitable sign of enjoyment as compared to posed smiles (AU6 also occurs in posed DDs [11][17]), but it was shown that the action of the AU6 plays an important role in the perception of spontaneity, authenticity, genuineness of smiles and judgment accuracy [30][31][32][33].

2 [15][19][25][34] defined the basis of joyful laughter (Duchenne laughter) to consist of a DD plus an audible, laughter-related vocalization and open mouth. DD laughter is typically lasting longer than DD smiling, and entails a more intense contraction of the zygomatic major muscle. Besides, laughter is a more complex behavior than smiling and not only facial parameters, but also lacrimation, respiration, body movements, body posture, and vocalization (phonation, resonance, articulation) 
need to be considered [5].

While many authors have worked on the occurrence of smiling in varying lists of positive emotions, laughter has been widely neglected in former approaches. Laughter was linked to the expression of amusement3 [5] but to date, no agreement exists on other (positive) emotional elicitors of laughter and whether these laughs differ in their morphology [36]. Still, there are hints in the literature that more emotions than amusement co-occur with laughter. In a recent study, Platt and colleagues [24] found that participants reported to express laughter when feeling schadenfreude, amusement, tactile pleasure, relief, as well as wonder. Furthermore, these emotions were also linked to actually expressed higher intensity DDs in an interview. Thus, the current study aims to test which positive emotions go along with laughter, as compared to positive emotions being inclined to go along with smiling.

\subsection{What is known about the expression of the 16 enjoyable emotions proposed by Ekman?}

As the knowledge on smiling and laughter in positive emotions is scattered, we include a brief review on what is known about the expression of the 16 enjoyable emotions described by Ekman [1]. Although we are not claiming that this is an exhaustive list of all possible positive emotions, it is however the most inclusive list with hypothesized facial expressions. We first review the literature on emotions that have been claimed to go along with laughter, followed by a review of the literature concerned with the remaining positive emotions.

Amusement is the positive emotion that has been most often related to laughter (or used as an elicitor of laughter [37]). Higher intensity of felt amusement was found to correlate with laughter, whereas lower intensities correlated with smiling [5][19]. Although laughter and smiling were viewed as displays with a different phylogenetic origin, van Hooff [94] claimed that they have converged considerably in Homo species. Van Hooff stated: "Human laughter and smiling also appear to shade into each other quite smoothly. They are undoubtedly highly associated temporally and they are at least to a certain extent conceptually interchangeable. From a purely morphological viewpoint our laughter can roughly be considered as an intermediate of the classical primate relaxed open-mouth display and the silent bared-teeth face (e.g., chimpanzee open-mouth form), and the smile as a weaker form of it." (p. 226). Although van Hooff remarked that the two displays converge considerably, he stated that there might be situations where they are not inter-changeable. This is important for the current study for two reasons. Firstly, it is assumed that smiling and laughter typically occur at different intensities of amusement (in line with van Hooff's claim of convergence): Smiling at lower levels of intensity and laughter at higher levels of intensity. Secondly, it is expected that certain emotions have an alignment with laughter and thus the smiling and laughter displays are not solely a function of the intensity, but are linked to the structure of a given emotion (and though not always interchangeable, in line with the claims of van Hooff).

There are various accounts that other positive emotions than amusement co-occur with laughter as well, but their study has been much less systematic than research on amusement. Schadenfreude, relief, tactile pleasure, and pride (in ones own achievements) were postulated to cooccur with laughter too [24]. Examining vocal features, [38] suggested that schadenfreude elicits a recognizably distinct auditory laughter quality (when encoded in actors portraying laughter and decoded above chance accuracy by raters). For the face, [39] reported that the experience of schadenfreude correlated with smiles measured by facial EMG. We thus assume that a similar relationship between emotion intensity and the expression of smiling and laughter could be found in schadenfreude, as it was postulated for amusement, see [19]: Higher intensity of felt schadenfreude is hypothesized to co-occur with laughter, whereas lower intensities co-occur with smiling.

Yet, two factors complicate the study of schadenfreude expressions: First, it might not be socially accepted to laugh at the misfortunes of others, e.g. [1]. Therefore, people might try to down-regulate the joy expression in schadenfreude [36]. Second, schadenfreude often seems to be blended with amusement, as some authors utilized "funny" mishaps to elicit schadenfreude in participants [40]. Therefore, it is also unknown whether potential smiling and laughter in schadenfreude is due to the amusing elements of the eliciting stimuli.

Relief was expected to go along with the release of a tense state, with vocalizations like laughter and/or deep in-and exhalations and sighs [41]. [42] found the "enjoyment of relief" in infants related to smiling. Furthermore, [43] and [44] discussed the tension-release in relief and linked it to the expression of laughter. The latter author described relief laughter being of irregular rhythm and with rather static facial expressions, provoked by a relief of anxiety, preceded and followed by smiling. Conversely, [45] assigned relief a low arousal with facial displays of lower intensity (with low intensity smiling being the most frequently shown prototype of relief; but little involvement of the orbicularis oculi pars orbitalis muscle). Thus, relief might go along with smiling and laughter.

As one form of tactile pleasure, tickling was observed to elicit DD smiling and laughter [14][46], indicating that pleasant tactile stimulation elicits facial markers of joy. Tickling has also been observed to co-occur with laughter-like vocalizations in primates and rats [3] [47]. Otherwise, tactile stimulation through massage has been shown to decrease heart rate and arousal, e.g. [48]. Thus, tactile pleasure might elicit both, smiling and laughter, depending on the eliciting stimulus.

Next, the remaining facets of enjoyable emotion after Ekman [1] are shortly described in terms of knowledge about the facial expression. Starting with fiero and naches, although they are not synonymous with pride (the former two being more specific), they may share facial features:

3 The sixteen enjoyable emotions cover five sensory pleasures (i.e., tactile, olfactory, auditory, visual, and gustatory) and amusement, contentment, excitement, relief, wonder, ecstasy (self-transcendent rapture), fiero (pride in ones own achievements), naches (pride in the achievements of others, with whom you have a relationship), elevation, gratitude, and schadenfreude (the joy of a rivals misfortune). Ekman suggests that the 16 enjoyable emotions may not have unique signal value, but instead share the DD which may differ in temporal features or intensity [1]. 
In studies on pride in gold medal winners of Olympic games, sighted, congenitally, and non-congenitally blind gold medal winners showed DDs [49]. As these victories were linked to the sportsmen's own achievements, it is likely to be pride in one's own achievement (fiero in Ekman's conceptualization). [50] had actors portraying seven basic emotions, as well as embarrassment and pride. They found that embarrassment, joy, and pride were expressed by laughter, although there were some gender differences in the portrayals. While both males and females $(100 \%)$ expressed joy by laughter, $25 \%$ of the females, and $50 \%$ of the males expressed pride by laughter ("haHA" was uttered $50 \%$ in females, and $75 \%$ in males). Furthermore, pride was found to entail (DD-) smiles (sometimes with compressed lips), head tilt back, arms on chest or on hips, and other postural elements like straightening of the back and pulling back of the shoulders to expose the chest [21][22][26][51][52]. Thus, fiero /naches might go along with smiling, as well as laughter.

Other than for tactile pleasure, for the remaining sensory pleasures, contentment, gratitude, wonder, ecstasy, and elevation, smiling was postulated as the predominant facial expression. Sensory pleasures were postulated to elicit DDs [4] and maybe a vocalization [41]. For example, in visual pleasure, participants showed DDs when looking at flowers [53]. [54] mentioned the occurrence of smiling in contentment and satisfaction, but mentioned that those smiles would not lead into laughter (indicating the low arousal linked to those feeling states). For contentment and gratitude, [24] found DD smiling of lower intensities occurring. Still, it was also doubted whether these two emotions elicit any facial displays at all: [55] argued that changes in contentment may be more cognitive than physical, and [1] assumed that the facial muscles may relax instead of contracting. [44] linked contentment to inactivity (as its inherent action tendency) and the function of recuperation. For serenity, an emotion similar to contentment, [56] found the activation of the zygomatic major muscle in low intensities, but no orbicularis oculi pars orbitalis muscle or mouth opening. For gratitude, bowing of the head and verbal expressions have been identified, but no distinct facial cues in posing studies [35][57]. Thus, contentment and gratitude are hypothesized to elicit low intensity smiling.

Lower intensity smiling was also expected for wonder, ecstasy, and elevation. For wonder, Darwin [3] expected goose bumps to occur and Ekman [1] describes the occurrence of tingling on the shoulders and the back of the neck, head shaking, deep inhalation, and exhalation. The emotion most similar to wonder in its definitional elements that has received empirical attention on its expressive features is awe, see [26]. Posed displays of awe frequently included raised inner eyebrow, widened eyes, and an open, slightly drop-jawed mouth. A slight forward jutting of the head and visible inhalation were also common elements of the posed displays [26]. Furthermore, [26] noticed that only few people smiled when posing displays of awe. In the pioneering work on facial expressions by Duchenne de Boulogne [58] ecstasy was described as being expressed with upward and lateral gazes. [24] found lower intensity DDs occurring with ecstasy, but to our knowledge, no further empirical evidence on facial features of ecstasy exist. Similarly, little is known about the expression of elevation. Algoe and Haidt [59] reported that participants associated laughter with amusement, but not elevation, indicating that elevation is not typically expressed by laughter. Like contentment, elevation was associated with muscle relaxation. Yet, those emotions share the DD in different intensities and maybe temporal features [24].

\section{THE PRESENT STUDY}

The present study aimed at inducing memories of the 16 enjoyable emotions (based on the list proposed by Ekman [1] $)_{4}$ and consequently assess the facial expressions and laughter-vocalizations of the story-tellers. Facial expressions were assessed with the Facial Action Coding System (FACS [2]). We opted for a rather "natural" elicitation setting by inducing the positive emotions through emotion recall in a group situation. We do acknowledge that in such an elicitation setting, the participants may feel different emotions relating to elements of their emotion memory, the group, as well as the intended emotion, see [60]. Also, facial expressions may also be influenced by the social context, emotion regulation, display rules, and strategic self-presentation [21][22]. Still, our setting allowed for the comparison of the frequency and intensity of the different smiles and laughs that were elicited across the 16 emotions. The current study goes beyond the approach utilized by [24] by investigating not only facial, but also vocal features (laughter vocalizations) and by utilizing a more naturalistic emotion induction technique.

First, we investigated exploratively whether positive emotions could be differentiated by the frequency of smiling and laughter they elicit. Second, we investigated whether positive emotions could be differentiated by the intensity of smiling and laughter they elicit. Based on the review of the literature, Hypothesis 1 assumed that contentment, gratitude, elevation, ecstasy, and the sensory pleasures would elicit less intense smiles (and laughs) than emotions that have been found or postulated to cooccur with laughter (e.g., amusement, schadenfreude). Moreover, to validate our findings, we aimed at comparing the current findings to the findings of [24]. Thus, hypothesis 2 stated that the five emotions going along with higher display intensities found by [24] should also go along with higher display intensities compared to the remaining 11 emotions in this study.

Third, with respect to the dominance of occurence of laughter compared to smiling, we assumed that amusement (3a), schadenfreude (3b), wonder (3c), relief (3d), and tactile pleasure (3e) co-occur with higher amounts of laughter than smiling, compared to the other 11 emotions (hypothesis 3a-e). Fourth, we included smiling and laughter displays that did not fulfill the criteria for Duchenne Displays (DD), but contained markers of displays regulation as for example in the case of schadenfreude, people are likely to down-regulate the genuine joy because it is not 
appropriate to laugh at other's misfortunes in social situations [1] [36]. Thus, individuals would indeed experience and express joy, but these regulated displays would not fulfill the criteria for DD and thus be typically excluded from analyzing "pure" joy displays. We hypothesized that the regulated displays would resemble the unregulated ones in their intensity (thus being positively correlated, hypothesis 4). Then, we exploratively investigated whether the rank order of emotions in terms of elicited smiling/laughter intensity would change if the displays including further markers were included too.

\section{Method}

\subsection{Participants}

The sample consisted of 22 Swiss German participants. They were assigned to six conversation groups. Within the groups, the participants were of similar age (groups with individuals between 20 - 25 years, $29-32$ years, or 38 - 58 years). Each conversation group consisted of three to four participants (10 males, 12 females; ages ranging from $19-58 ; M=36.25, S D=13.02)$. With respect to participant's age, a one-way ANOVA indicated no difference in the intensity of the zygomatic major muscle action among three age groups, $F(2,800)=0.21, p=.811$.

\subsection{6 enjoyable emotions story telling task}

This task aims at inducing 16 positive emotions by emotion recall of an intense event of ones' life when the respective emotion was felt [95]. First, participants were provided with a description of Ekman's [1] 16 enjoyable emotions via e-mail. The description entailed the respective emotion name, a short description and an example (see Appendix 2). To prepare for the group conversation session, participants were asked to memorize an event of each of the emotions from their previous experiences. They were encouraged to take notes at home and instructed to remember the event as vividly as possible: trying to recall the feelings, thoughts, and actions. Second, approximately two weeks later participants were invited for a session at the university for the group conversation. At the session, they were first asked whether they had completed the task and then asked to join the group conversation. The group conversation followed a structured procedure: the experimenter randomly chose an emotion, named it and all participants told their emotion memory sequentially. Then, the next emotion was chosen. Participants were instructed to pay attention to the stories of the other group members, but not interfere with the story-telling. The order of the story-tellers and emotions was randomized by the experimenter. While telling the memories, two non-obtrusive cameras recorded the facial responses of the story-tellers frontally.

\subsection{Facial measurements}

The Facial Action Coding System [2] is an anatomically based method allowing the coding of 44 visually discernible action units (AU), which may be coded in frequency, intensity, timing, duration, laterality, symmetry, and cooccurrence with other AUs. The intensities range from trace (coded as A) to maximum (E, no further stretching, bulging, pouching is possible [2]). Following the procedure of [63], all apex times of smiles and laughs (apex of the zygomatic major muscle action; AU12; Lip Corner Puller) were coded by two FACS certified coders who did not know the specific hypotheses of the experiment. Consequently, smiles and laughs could be categorized as DDs (simultaneous and symmetric AU6 and AU12, plus potentially an AU7, AU25, AU26, AU275, but no other action unit) and non-DDs (other smiles containing an AU12; incl. smiles not containing a symmetric AU6 of the same intensity as the AU12 and smiles entailing additional markers). Furthermore, two sets of inter-rater reliability codings were conducted. Firstly, 37 randomly chosen emotion story clips (12\% of the sample) were double coded to assess the agreement with respect to AU presence/absence. The tolerance window of the apex time of the AU12 was 0.5s. The inter-rater reliability (IRR; Cohen' $k$ ) by two coders was .84 . Secondly, we conducted an independent control coding of another 30 videos by a coder blind to the hypotheses of the study and we calculated the IRR by considering any omission in terms of AU presence as well as any deviation in intensity scores. The mean IRR was .89, with the Kappa's ranging from .67 1.00. Both Kappas indicate good reliability of the coding.

\subsection{Procedure}

Participants were recruited (flyers, mailing-lists) for a study on 16 enjoyable emotions. After agreeing to participate in the study, participants were given a date for a session at the university (approx. two weeks later) and provided with a description of the 16 positive emotions after Ekman [1] via e-mail (see 16 enjoyable emotions story telling task, Appendix 2). After completing the home assignment, they were invited for a session in the lab. For data collection, groups were built a priori according to participant's age (20-25 years, 29-32 years, 38-58 years) to avoid dominance hierarchy occuring within mixed aged groupings. At the session, participants were introduced to each other and informed about the session's agenda. All participants gave written consent to being filmed and the film material being used. Then, participants were sat at a square table, facing each other, with two cameras behind the participants on each side filming each participant frontally (close up on head and shoulders). Then, the 16 enjoyable emotions story telling task was completed. The sessions lasted approx. 120 minutes.

4 While discrete positive emotion approaches (such as Ekman's) suggest a categorical organization of emotions, dimensional approaches suggest that emotions could be organized along a number of dimensions, such as valence and arousal [61][62]. In the current approach, our focus lay in the comparison of 16 enjoyable emotions with respect to the smiles and laughs they elicit, while leaving the question of gradual or categorical differences between positive emotions aside.

5 Action Unit descriptions and muscle involvement following the FACS manual [2]: Possible Action Units for DDs: AU12 = Lip Corner Puller, zygomatic major muscle. AU6 = Cheek Raiser, orbicularis oculi pars orbitalis muscle. AU7 = Lid Tightener, orbicularis oculi pars palebralis muscle. AU25 = Lips Part, depressor labii muscle, or relaxation of mentalis, or orbicularis oris muscles. AU26 = Jaw Drop, masetter muscle, temporal and internal pterygoid muscle relaxed. AU27 = Mouth Stretch, pterygoids digastric muscle. Further Action Units coded: AU1 = Inner Brow Raise, frontalis pars medialis muscle. AU2 = Outer Brow Raiser, frontalis pars lateralis muscle. AU5 = Upper Lid Raiser, levator palpebrae superioris muscle. AU4 = Brow Lowerer, depressor glabellae muscle, depressor supercilli muscle, and corrugator muscle. AU9 = 
Nose Wrinkler, levator labii superioris alaeque nasi muscle. AU14 = Dimpler, buccinators muscle. AU15 = Lip Corner Depressor, triangularis muscle. AU16 = Lower Lip Depressor, depressor labii muscle. AU17 = Chin Raiser, mentalis muscle. AU20 $=$ Lip Stretcher, risorius muscle. AU23 = Lip Tightener, orbicularis oris muscle. AU24 = Lip Presser, orbicularis oris muscle. AU28 = Lip Suck, orbicularis oris muscle.

6 The dataset utilized in this study can be obtained for research purposes (i.e., computational models of laughter). Please send your request to J. Hofmann.

Facial expressions and vocalizations were recorded during the structured group conversations. All clips were trimmed (Final Cut Pro) and tagged digitally with a time code. Two certified coders coded the 310 emotion story clips with the FACS. Only the facial actions occurring during the telling of a story were considered. No facial actions in response to other participant's laughter or comments were considered, as facial expressions during additional conversation were not necessarily related to the emotion memory and thus to the target emotion.

Facial variables were formed for responses to every recorded memory separately. First, all displays entailing an AU12 were coded at their apex, with all AUs occurring at this apex. If participants were speaking (AU50), 12A was not considered, as the feature changes of the mouth could have been due to the speaking (the same was applied to other AUs of the mouth region, see [2]). Second, DDs (symmetric and simultaneous contraction of AU6 and AU12) were derived in frequency and intensity. Third, the combination of a DD or a non-DD and a vocalization was operationalized as DD or non-DD laughter [5]. In laughter vocalizations, single or multiple (e.g., "ha" or "ha ha ha") as well as phonated or non-phonated audible exhalations were distinguished.

If a given laughter entailed phonated and nonphonated elements, it was categorized as phonated. Single laughter-related exhalations (i.e., through the nose) were treated as single, unvoiced laughter vocalizations. The number of laughter vocalizations was coded. Fourth, smiles and laughs beyond the DD (non-DD) were identified if they entailed AUs extending the definition of a DD at the apex of the AU12 (i.e., markers for smile controls counteracting the upward action of the AU12 or obscuring the smile [34] and indicators of the control of the joy expression [4]; e.g., AU14, AU15, AU17, AU18, AU23, AU24, AU28).

\section{Results}

\subsection{Preliminary analyses}

A total of 341 emotion stories was obtained. 11 stories were not recorded due to technical problems. Out of all emotion story clips, 310 were used: 31 stories were discarded for several reasons: a) participant turned away from camera, b) bad sound quality; e.g., participant's emotion story was not understood, c) the participant could not recall an event where the positive emotion occurred, and d) the participant reported never to have had experienced the respective emotion. For each emotion, 17 to 22 emotion stories were available (total duration of all clips $246 \mathrm{~min} 44 \mathrm{~s}$; the number of stories per emotion is reported in Table 2). The average duration of an emotion story was 55s, ranging from $20 \mathrm{~s}$ to $1 \mathrm{~min} 28 \mathrm{~s}$ (emotions did not differ in the average duration of the stories, $F(15$,
75) $=0.79, p=.682$

In the 310 emotion stories, 544 smiles and 288 laughs were coded. For the analysis, 19 smile and laughter events within an emotion recall were excluded, as the participants smiled or laughed because of an emotion memory unrelated event (i.e., making a joke after recalling the emotion memory). The remaining 533 smiles and 280 laughs, were categorized as DDs (simultaneous and symmetric AU6 and AU12, plus AU7, AU25, AU26, AU27), and non-DDs: smiles and laughs with further AU's beyond the definition of DD (112 smiles and 71 laughs were identified to contain one or more further $\mathrm{AUs}_{6}$ ) and smiles/laughs containing of a symmetric AU12B (or of higher intensity) without AU6 (56 smiles and laughs).

Mean values for the frequency of smiling and laughter were obtained by dividing the number of displays by the number of emotion stories for the respective emotion category. This was preferred over averaging by speaking time, as every memory is a meaningful unit: some emotion memories need a longer build up and context to tell than others. Averaging by speaking time would therefore disadvantage emotions that require more explanations to be described in a story (i.e., a wonder story needs more build up about the time, place, setting, background, social context than recalling a funny moment that elicited amusement). Concerning the features of laughter, four display configurations were possible: voiced or unvoiced single exclamations (e.g., "ha" or " $\mathrm{h}$ "), and voiced or unvoiced multiple laughter pulses [5]. In Table 1, the averaged numbers of each DD and non-DD laughter configuration per emotion story is reported ${ }^{6}$.

Table 1 shows the distribution of the different display categories over the 16 positive emotions. Next, these categories are evaluated for differences in their occurrence.

\subsection{Frequency of smiling and laughter}

Next, we investigated whether the 16 positive emotions differed in the frequency of elicited smiles and laughs (Table 1). Mean values and percentages for four smile and laughter categories (DD and non-DD smiles, DD and non-DD laughs) are given in Table 1.

Table 1 shows the standardized means of smiles and laughs for all emotions. On average, $M=2.64$ smiles or laughs occurred in each emotion memory $(S D=0.69$, Min $=1.68$, Max $=4.00$ ). It is noteworthy that for all 16 positive emotions, more DD smiles than non-DD smiles or laughs occurred (the non-parametric Friedman ANOVA with the four display categories revealed a significant main effect, $\chi^{2}[3]=40.25, p=.001$, all pairwise Wilcoxon comparisons for DD smiles were significant at $p=.001$ ). In general, DD laughs were more frequent than non-DD laughs, $\chi^{2}[1]=$ 16.00, $p=.001$, (see Table 1). Within Duchenne laughs, multiple, voiced laughter vocalizations were more frequent than unvoiced multiple exclamations, and single exclamations (both voiced and unvoiced), with the latter having the lowest frequencies, $\chi^{2}[3]=27.08, p=.001$ (Wilcoxon pairwise-comparisons all $p=.001)$. Multiple unvoiced exclamations and single vocalizations (phonated or not) were similarly frequent $(p>.448)$. 
TABLE 1

StANDARDIZEd FREQUENCIES OF DD AND NON-DD SMILES AND LAUGHS FOR THE 16 Positive EMOTIONS.

\begin{tabular}{|c|c|c|c|c|c|c|c|c|c|c|c|c|c|c|c|c|}
\hline Type & 를 & $\begin{array}{l}\frac{2}{3} \\
\frac{\ddot{g}}{0}\end{array}$ & 总 & $\begin{array}{l}\text { है } \\
\text { हू } \\
\text { हूँ } \\
\text { है }\end{array}$ & 商 & 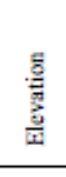 & 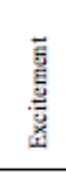 & 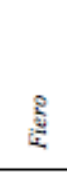 & 氖 & $\begin{array}{l}\text { हू } \\
\frac{\mathrm{g}}{\mathrm{N}} \\
\text { है }\end{array}$ & $\frac{\mathrm{g}}{\mathrm{g}}$ & $\frac{\mathrm{g}}{\check{\Xi}}$ & 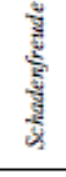 & $\frac{\text { 젼 }}{3}$ & 晜 & $\begin{array}{l}\overrightarrow{\mathrm{g}} \\
\text { है } \\
\text { है } \\
\text { है }\end{array}$ \\
\hline DD smile & 1.05 & 1.33 & 1.05 & 1.48 & 1.56 & 1.23 & 1.75 & 1.83 & 1.48 & 0.94 & 1.58 & 1.57 & 1.41 & 1.22 & 1.10 & 1.17 \\
\hline Non-DD smile & 0.21 & 0.38 & 0.30 & 0.29 & 0.22 & 0.36 & 0.75 & 0.28 & 0.24 & 0.29 & 0.53 & 0.43 & 0.24 & 0.56 & 0.35 & 0.28 \\
\hline DD laugh & 0.42 & 0.43 & 0.35 & 0.43 & 0.78 & 0.55 & 0.95 & 0.67 & 0.38 & 0.82 & 0.47 & 0.62 & 1.29 & 0.33 & 0.85 & 1.67 \\
\hline Non-DD laugh & 0.00 & 0.33 & 0.00 & 0.10 & 0.39 & 0.00 & 0.05 & 0.33 & 0.10 & 0.24 & 0.21 & 0.10 & 0.82 & 0.06 & 0.25 & 0.89 \\
\hline DD total & 1.47 & 1.76 & 1.40 & 1.90 & 2.33 & 1.77 & 2.70 & 2.50 & 1.86 & 1.76 & 2.05 & 2.19 & 2.71 & 1.56 & 1.95 & 2.83 \\
\hline Non-DD total & 0.21 & 0.71 & 0.30 & 0.38 & 0.61 & 0.36 & 0.80 & 0.61 & 0.33 & 0.53 & 0.74 & 0.52 & 1.06 & 0.61 & 0.60 & 1.17 \\
\hline \multicolumn{17}{|l|}{ DD Vocalizations } \\
\hline Single Unvoiced & 0.05 & 0.00 & 0.05 & 0.00 & 0.06 & 0.18 & 0.15 & 0.06 & 0.10 & 0.18 & 0.16 & 0.24 & 0.00 & 0.00 & 0.10 & 0.17 \\
\hline Single Voiced & 0.05 & 0.05 & 0.00 & 0.19 & 0.22 & 0.00 & 0.15 & 0.17 & 0.00 & 0.00 & 0.11 & 0.14 & 0.00 & 0.11 & 0.25 & 0.28 \\
\hline Multiple Voiced & 0.26 & 0.24 & 0.25 & 0.24 & 0.39 & 0.36 & 0.25 & 0.39 & 0.29 & 0.53 & 0.21 & 0.19 & 0.65 & 0.11 & 0.35 & 0.67 \\
\hline $\begin{array}{l}\text { Mult. Unvoiced } \\
\text { Non-DD } \\
\text { Vocalizations }\end{array}$ & 0.05 & 0.14 & 0.05 & 0.00 & 0.11 & 0.00 & 0.10 & 0.06 & 0.00 & 0.12 & 0.00 & 0.05 & 0.06 & 0.11 & 0.10 & 0.56 \\
\hline Single Unvoiced & 0.00 & 0.00 & 0.00 & 0.00 & 0.00 & 0.00 & 0.00 & 0.00 & 0.00 & 0.00 & 0.00 & 0.00 & 0.00 & 0.00 & 0.00 & 0.00 \\
\hline Single Voiced & 0.00 & 0.00 & 0.00 & 0.00 & 0.00 & 0.00 & 0.00 & 0.00 & 0.05 & 0.00 & 0.16 & 0.00 & 0.00 & 0.00 & 0.00 & 0.00 \\
\hline Mult. Unvoiced & 0.00 & 0.00 & 0.00 & 0.00 & 0.06 & 0.00 & 0.00 & 0.06 & 0.00 & 0.00 & 0.00 & 0.00 & 0.06 & 0.00 & 0.00 & 0.06 \\
\hline Multiple Voiced & 0.05 & 0.33 & 0.00 & 0.05 & 0.33 & 0.00 & 0.05 & 0.28 & 0.05 & 0.24 & 0.05 & 0.10 & 0.76 & 0.06 & 0.10 & 0.83 \\
\hline
\end{tabular}

Note. All smiling and laughter frequency values were standardized for the total amount of emotion stories obtained for each positive emotion. DD $=$ Duchenne Display. Non-DD = Displays with facial markers beyond the DD. Single $=$ single laughter exclamation. Multiple $=$ multiple laughter exclamations.

Interestingly, multiple unvoiced DD laughs occurred predominantly in amusement. Within non-Duchenne laughs, multiple, vocalized laughs were more frequent than multiple unvoiced and single exclamations (both voiced or unvoiced), $x^{2}[3]=31.27, p=.001$ (Wilcoxon pairwise-comparisons all $p=.001$ ). Multiple, voiced nonDD laughs occurred predominantly in schadenfreude and amusement. Convergent to the findings on the DD laughs, the multiple unvoiced laughs and single exclamations did not differ in their frequency within the nonDuchenne laughs $(p>.059)$. All emotions elicited smiles and laughs, in line with our predictions. Numerically most smiles and laughs occurred in amusement, schadenfreude, and excitement, and least in tactile and auditory pleasure.

\subsection{Hypotheses 1 and 2: Display intensity of smiling and laughter}

For a preliminary screening, it was investigated whether DD smiles and DD laughs differed in the intensity of AU12 (lip corner pulling), AU6 (cheek raising) and AU25 (mouth opening), as suggested in the literature [19], with laughter going along with higher intensities in AU12, AU6 and AU25. In line with the assumptions, three t-tests (type of display: smile vs. laugh as factor and the FACS determined intensity of the display as the depend- ent variable) indicated that the intensity of AU12 in DD laughter $(M=3.57, S D=0.81)$ was higher than in $\mathrm{DD}$ smiling $(M=2.14, S D=0.76), t(786)=-16.21, p<.001$. This was also true for cheek raising (AU6) and mouth opening (AU25): DD laughter led to more intense AU6 $(M=2.72$, $S D=0.91)$ than smiling $(M=1.94, S D=0.76), t(684)=$ $9.88, p<.001$; and laughter led to more intense mouth opening $(M=3.10, S D=0.98)$, than DD smiling $(M=2.46$, $S D=0.75), t(462)=-9.15, p<.001$.

To test hypothesis 1 , checking for differences in the intensity of the DD smiling and laughter expressions in 16 positive emotions (non-DDs were excluded), we computed an ANOVA with the type of positive emotion (16 positive emotions) as factor and the intensity of the display7 as dependent variable. For the post-hoc tests, a Bonferroni correction was applied for the pairwise-comparisons. Fig. 1 shows the means and confidence intervals (95\%) for the display intensity for the 16 positive emotions.

An ANOVA with the intensity of the displays as dependent variable and the 16 emotions as repeated measures indicated a difference in the display intensities, $F(15,533)=3.82, p<.001, \eta_{p}^{2}=.097$ (Fig. 1)

7 For the display intensity, a score consisting of the intensity of the AU12 as basis, plus adding one scale point if laughter occurred was computed (following the procedure of Ruch 1997; and similarly [64]). The computation of this score follows the theoretical notion that smiling and laughter represent different intensities of exhilaration/joy in humans [19]. 


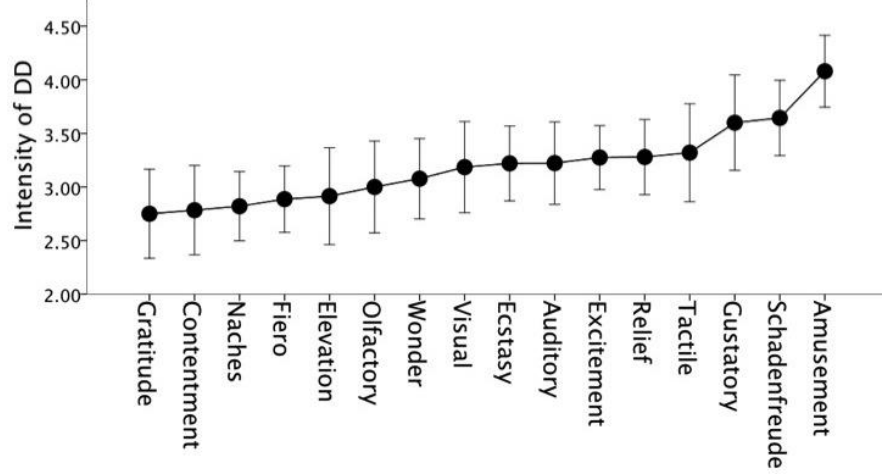

Fig. 1. Means and confidence intervals (95\%) of the intensity of the DD displays for the 16 positive emotions

Post-hoc pairwise comparisons showed that amusement was significantly higher in intensity than all emotions but schadenfreude and gustatory pleasure. Schadenfreude was higher in intensity than gratitude and contentment. Gustatory pleasure differed from contentment and gratitude (all $p<.05$, Bonferroni corrected). All other emotions did not differ from each other in the intensity of the DD. Thus, hypothesis 1 was rejected.

To test hypothesis 2 , a contrast was computed to investigate the comparability of the results obtained in Platt et al. [24] to the current data. The five laughter-eliciting emotions identified by [24], namely amusement, schadenfreude, relief, tactile pleasure, and wonder were compared against all other emotions. The contrast was significant (equal variances assumed; $t(518)=-4.16, p<.001$ ). Thus, hypothesis 2 was confirmed as we could replicate the findings by [24].

\subsection{Hypothesis 3: Laughter}

Next, we investigated whether some emotions had a stronger co-occurrence with laughter than others. Hypothesis 3 (a-e) assumed that amusement, schadenfreude, wonder, relief and tactile pleasure should elicit more smiling than laughter. First, we computed the percentage of emotion memories that contained any laughter (binary coding; for each emotion memory it was determined whether any laughter had occurred or not. Scores were summed up and divided by the total amount of memories per emotion). In $72 \%$ of the amusement and $71 \%$ of the schadenfreude stories, any laughter occurred. Followed by fiero $(61 \%)$, gustatory pleasure $(58 \%)$, ecstasy $(55 \%)$, and wonder $(45 \%)$, olfactory pleasure and naches (both $42 \%$ ), elevation $(36 \%)$, excitement and auditory pleasure (both $35 \%$ ), relief and gratitude (both $33 \%$ ), visual pleasure $(27 \%)$, tactile pleasure $(26 \%)$, and contentment $(19 \%)$. We hypothesize that due to the nature of the group conversation setting, all emotions elicit at least a small percentage of laughter. Still, the top scoring emotions amusement and schadenfreude co-occurred with laughter in threequarters of the emotion memories recalled and thus showed a high laughter occurrence. Second, we comput- ed how many laughs were shown in relation to all smiles and laughter (i.e., all joy-related displays). Fig. 2 shows the ratio of laughter to all displays shown (laughs/all smiling and laughter displays), with values above 0.5 indicating more laughs than smiles, and values below 0.5 indicating higher numbers of smiles than laughs. A 0.5 score indicates an equal number of smiles and laughs.

In respect to the relative frequency of smiling and laughter (see Fig. 2), all positive emotions but two revealed a pattern of higher frequency of smiling compared to laughter. Fig. 2 shows that for amusement (36.11\% smiles, $63.89 \%$ laughs) and schadenfreude (43.75\% smiles, $56.25 \%$ laughs) more laughs than smiles occurred. Visual pleasure elicited numerically least laughs in relation to smiles (71.43\% smiles, $28.57 \%$ laughs). A Chi-Square test $\left(X^{2}[15]=67.93, p=.001\right)$ indicated a significant difference in the distribution of smiling and laughter over the 16 positive emotions: for amusement and schadenfreude, laughter was more frequent than smiling (confirming $3 a$ and $3 b$ ), and for visual pleasure, smiling was more frequent than laughter (all differing at $p<.05$ ). Thus, although both, smiling and laughter occurred in all 16 positive emotions (maybe also due to the chosen method of a group conversation setting), it is clearly shown that not only amusement, but at least also schadenfreude more often co-occurs with laughter (eliciting laughs in over $70 \%$ of the emotion stories), confirming $\mathrm{H} 3 \mathrm{a}$ and H3b. Nevertheless, $\mathrm{H} 3 \mathrm{c}$ to $\mathrm{H} 3 \mathrm{e}$ were disconfirmed: wonder, relief and tactile pleasure did not elicit more smiling than laughter.

\subsection{Hypothesis 4 and explorative analysis: Display regulation}

So far, only pure DDs were considered for the analysis, systematically excluding displays where the joy expression is regulated (i.e., containing smile controls and markers that regulate the upward action of the AU12 [34]) or contains additional facial markers beyond the DD. This is problematic as for example in the case of schadenfreude, where people are likely to down-regulate the genuine joy because it is not appropriate to laugh at other's misfortunes in social situations [1][36].

We computed a Pearson correlation between the pure DDs and the smiles and laughs containing the DD markers but also smile controls. The intensities of the two display categories correlated positively, $r(16)=.80, p<.001$, indicating that the regulated displays resembled the pure DDs in the elicited intensity and thus confirming hypothesis 4. Furthermore, we performed an ANOVA with the type of positive emotion as factor and the intensity of all smile and laughter displays (DD and non-DD smiles and laughs with smile regulation markers and smile controls, while excluding smiles/laughs lacking an AU6) as dependent variable. Fig. 3 shows the means and confidence intervals $(95 \%)$ for the displays including the regulated displays. 
Fig. 3 shows that the positive emotions differed from each other in their display intensity, $F(15,787)=6.64, p<$ $.001, \eta_{p}^{2}=.114$. The post-hoc comparisons showed that amusement and schadenfreude differed from the other emotions: Amusement differed from all but gustatory pleasure and schadenfreude. Schadenfreude differed from contentment, gratitude, elevation, excitement, fiero, naches, and wonder. All other emotions did not differ from each other. For further investigation, we computed a contrast, comparing the five laughter-eliciting emotions identified by Platt et al. [24] against all other positive emotions. The contrast was significant (equal variances assumed; $t(771)$ $=-4.99, p<.001)$. This analysis showed that including regulation markers did not obscure the findings.

\section{Discussion}

The current study, most importantly, showed that smiles and laughs did indeed occur for all 16 positive emotions. Also, the Duchenne Display was observed in all of the positive emotions. This may be seen as a confirmation of Ekman's [1] claim, that all positive emotions may share the DD (in the sense of being a "family of emotions", Ekman 1994). In more detail, differences in the frequency of the displayed smiling and laughter were found. Duchenne smiles were more frequent than non-DD smiles or laughs. Duchenne laughs with multiple, unvoiced exclamations were predominantly found in amusement and non-DD laughs with multiple, voiced exclamations were predominantly found in schadenfreude.

Our results on the intensity of smiling and laughter were in line with earlier work on the 16 positive emotions proposed by Ekman [24], in line with hypothesis 2. We could also show that the five formerly identified emotions eliciting highest Duchenne Displays (amusement, schadenfreude, wonder, tactile pleasure, and relief), also differed in their intensity of Duchenne Displays (and also nonDuchenne Displays) from the other eleven emotions in the current study. Furthermore, the 16 positive emotions differed in their propensity to induce laughter: amusement and schadenfreude most often co-occurred with laughter (but not relief, tactile pleasure and wonder, disconfirming hypothesis 3c-3e). Still, this finding supports earlier postulates on both emotions: amusement has been claimed to be the facet of joy most strongly linked to laughter ([19] and also [65] who found a 120:1 laughter ratio occurring in amusement compared to joy) and schadenfreude was identified as having a distinct auditory laughter pattern [38]. Also, fiero elicited laughter in $61 \%$ of the cases, going along with findings of [50] as well as [24].

The three emotions that lead to counter-intuitive results were relief, tactile pleasure, and wonder (hypotheses $3 c-3 e)$. They all co-occurred with laughter in about one third of the recalled memories, fewer than expected. On one hand, this might be due to the content of the stories, as it is expected that not all elicitors of tactile pleasure will readily elicit laughter, but maybe also relaxation (for example in massage). Also for relief, depending on the quality of the anticipated negative event that eventually does not occur, responses might be different. On the other

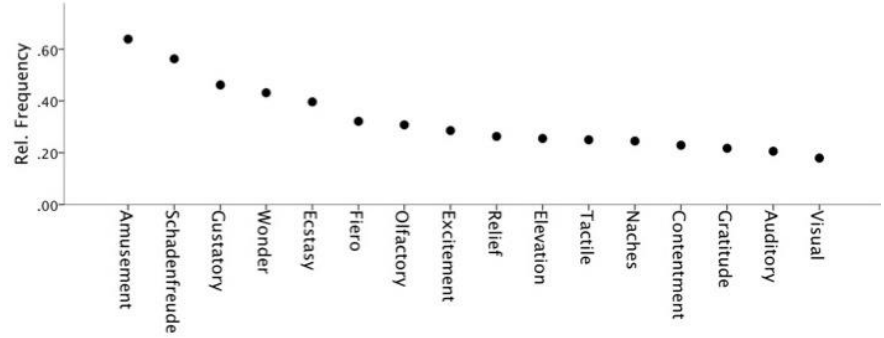

Fig. 2. Rel. Frequency = Relative frequency of laughter compared to all displays (all smiles and laughs) shown in 16 positive emotions

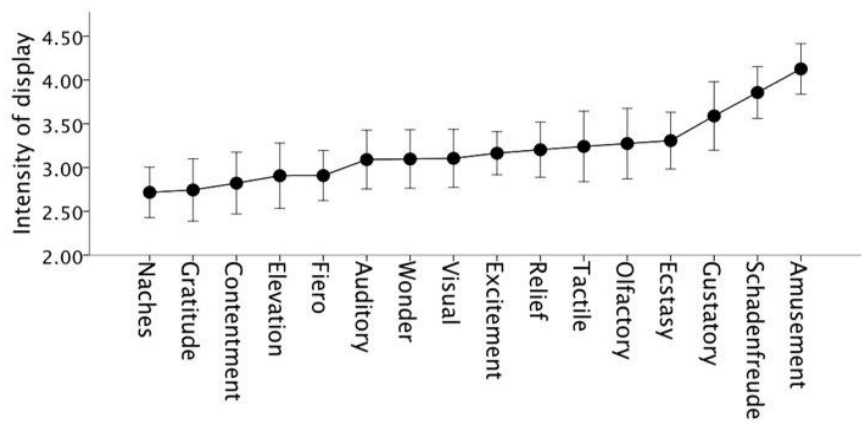

Fig. 3. Means and confidence intervals (95\%) of the intensity of the smiling and laughter displays (including displays with smile controls and regulating actions) for the 16 positive emotions

hand, the recall setting in the group might have led to altered cognitions, new feelings, and motivations that influenced the facial responses [60]. Particularly relief and wonder might be subject to a different appraisal when some time has passed after the emotion was experienced.

To summarize, amusement and schadenfreude showed a clear link to laughter. Whether the occurrence of laughter is linked to categorical differences in positive emotions (i.e., some emotions are laughter-eliciting, others not), or whether the occurrence of laughter is linked to the activation going along with certain emotions (indicating a dimensional approach), cannot be answered with the current data. Yet, this is one of few studies including a natural elicitation setting (vs. posed data) to suggest that laughter may link to more positive emotions than amusement and this needs further investigation.

Amusement evoked the highest intensity DDs, while contentment and gratitude evoked the least intense displays. This is in line with the literature: Amusement was found to be most often co-occurring with laughter [19] [65], and both contentment and gratitude were associated with low arousal and low intensity facial displays (or none at all, see [55]). Furthermore, research suggests that gratitude may be expressed through other channels, like the body (for bodily expressions of gratitude see [57]). Moreover, the emotions eliciting the highest intensity displays were convergent with findings by [24]. Still, the results extended earlier work. In particular, we considered fine-grained vocal markers of laughter, delivered more evidene of the occurrence of laughter in scahdenfreude, as well as the importance of assessing further facial markers, such as emotion expression regulation 
markers. Confirming hypothesis 4 , the displays including regulation markers were positively related to DDs in their intensity. This may suggest that those displays should not be excluded when looking at positive responses occurring with stories of positive emotion memories.

The current approach stressed the importance of looking at DDs and smiling and laughter displays that do contain the DD markers but also smile controls and regulation markers. This is important as certain emotions are typically being down-regulated in social situations, as they are deemed not acceptable to show (i.e., schadenfreude). We showed that for schadenfreude, high intensity displays of smiling and laughter are evoked, but many of the high intense displays were accompanied by regualtion markers in the structured group conversation setting. Especially in the case of the socially undesirable emotion of schadenfreude, the natural encoding can only be studied when individuals are unobserved, as it is assumed that there is no need to regulate the displays then. We hypothesize that in this case, schadenfreude will also be expressed by "pure" DDs [36]. Nevertheless, verbal ratings would need to ensure that participants do not regulate their displays when being alone due to an imagined audience.

Yet, other positive emotions might be subject to regulation too. Ekman, Friesen and Ellsworth [93] generally described four management techniques to control facial behavior (intensifying, de-intensifying, neutralizing and masking) and argued that display rules for each facial behavior specify what management technique should be applied by whom in what circumstance. Such display rules determine which of the 16 enjoyable emotions are regulated and why. For example, being on a strict diet may mean that individuals down-regulate the smile that goes along with the gustatory pleasure experienced when eating "a forbidden meal". Also, fiero (the pride in one's own achievements) might be down-regulated in the company of unfamiliar people in order to avoid to be seen as a show-off. In line with this, results from posing studies showed that displays of pride typically included a mild Duchenne smile with compressed lips (AU6, 70\%; AU12, 79\%; AU24, 60\% [26]). This implies that every emotion might be subject to down-regulation in a given social situation or depending on the elicitor. Yet, few emotions are generally socially not desirables, such as schadenfreude.

Moreover, there might be emotions that are generally harder to regulate than others. Excitement or relief may be harder to control, as they go along with an element of fearful anticipation or the anticipation of something negative. Ortony and Turner [92] argued that the expression of the intense positive emotions of relief is indistinguishable from that of extreme distress, with "extreme" emotions may be being harder to regulate. Lastly, some emotions might also be subject to up-regulation: Amusement must be down regulated when it occurs at an inappropriate time, at a funeral or any other serious situation. However, it can also be up-regulated when for example the boss makes a joke that you should find funny. The same would apply for relief, where displaying to others that a threat is over, would be beneficial to all involved. A similar argument would go for elevation, and naches and wonder, where sharing the experience is good for others. Futures studies may study the effect of up-and down-regulation on the expression of positive emotions more closely.

All of the explored positive emotions shared the DD, but differed in the display intensity and occurrence of laughter. This might explain why the recognition rates of positive emotions are often low (e.g., amusement had overall the best decoding accuracy among 12 emotions including joy, pride, pleasure, relief, interest, admiration, tenderness and surprise [66]; pride and happiness are often confused [52] or emotions involving weak smiles can be confused with neutral expressions [67] [68]). Whereas facial expressions of joy are rarely confused with other facial expressions of basic emotions [56], it might be that recognition rates from facial expressions among different positive emotions are smaller (or it might even be impossible to distinguish by facial expression) because they all share smiling and laughter displays. Furthermore, recognition rates will vary according to the stimuli: if for example a pure DD schadenfreude laugh stemming from an unobserved situation is presented, individuals might not decode it as such, as this display is usually regulated when observable in a social context.

The current study focused on the facial encoding of positive emotions in structured group settings of one culture. Although there are only few studies, evidence suggests that culture plays a role in the expression of positive emotions, in the en- as well as decoding [7] [69] [70]. Therefore, it might be that the same methodology would lead to different results in other cultural contexts (where also certain positive emotions are differently valued, see [71]). Still, many studies support the notion that smiling and laughter are the universal facial expressive features of joy [50] [72]. Our results indicated the occurrence of smiling in all 16 positive emotions, and laughter in some. Future studies may focus on assessing the 16 positive emotions in different cultural contexts as well as by studying groups of individuals familiar to each other (i.e., friends). We expect that the most interesting differences will occur in the dimension of expression regulation due to cultural display rules or group norms and the difficulty with which emotion stories are recalled, as some cultural contexts/norms within groups of friends may (de-) emphasize the experience of some emotions. Also, future studies may investigate gender differences in the expression of positive emotions, as found in acted portrayals [50].

\subsection{Limitations}

One limitation of the current approach is the neglect of assessing other facial expression markers (especially displays other than smiles and laughs) or more fine-grained vocal markers of positive emotions (other than laughter; see [73] [74] [75] [76], body features of emotion expression, touch [77] [78] or breathing patterns [79]). We argue that investigating facial expressions of emotions is a starting point, which can be built upon. Further research should investigate other modalities and their interplay in the expression of positive emotions. A second limitation concerns the set of emotions chosen: We focused on the 16 
positive emotions suggested by Ekman [1]. Though this list is very broad, some positive emotions that have received empirical attention lately were not included: love or love-tenderness [79] [80] [81] [82] [83] and interest [55]. We chose not to include love as it has been argued that it is a longer-lasting phenomenon containing a mix of emotions. Also, whereas emotions are short lived, love is not ([1][84] but also [85]; although some argue that love is a basic emotion [80][82][83]). Still, love and interest may be included in future studies, as they seem to entail specific nonverbal cues: [86] described that love was typically expressed by four nonverbal "affiliation cues" and also for interest, evidence suggests nonverbal expression markers including smiles [8] [21] [22] [87].

A third limitation concerns the emotion induction technique. The emotions were not directly elicited, but were induced by an emotion recall. This might be problematic if the expression of an emotion differs after a cognitive post-processing and re-evaluation of the event [44] [88]. For example, a relief example might get a post-hoc funny connotation if the person realizes that the situation seemed threatening at the time, but was actually harmless [89]. Thus, further studies should include more finegrained self-report manipulation measures, assessing for example how well the person recalled the event, how well they felt the emotion in question, whether they felt different emotions when re-telling the event, and the intensity of the feeling state in the original, as well as the re-call situation etc. Also, future studies might include control conditions where participants talk about negative emotions, in order to establish "base rates" of smiling and laughter in this kind of setting.

Furthermore, the emotions were elicited in a social context, and participants might have felt a variety of emotions or affective states, not only linked to the emotion memory, but also to the situation. Nevertheless, emotions are mostly shown in interactions, mixed with other emotions, cognitions, and social display rules (see [60] representing an interaction between "push" and "pull" effects, see [90]). Thus, the chosen setting may be considered more ecologically valid than the strictly controlled laboratory setting. Also, we explicitly tested the influence of the social situation on the expression of emotions that were postulated to be regulated in a social context (as not socially acceptable to show). Moreover, dimensional approaches have been shown to be fruitful for the description of milder forms of affective states (as compared to "full-blown" emotions, see [91]) as maybe found in this emotion recall scenario and may be considered in future studies.

\subsection{Conclusion}

To conclude, when talking about memories of the 16 positive emotions after Ekman [1] differences in display intensities of smiles and laughs and the occurrence of laughter occurred among the 16 emotions. Amusement and schadenfreude elicited most laughter when individuals recalled emotion memories. While the study cannot answer the question what positive emotions are (i.e., on which dimensions they differ, etc.), it showed that when recalling them in a group conversation, all of them went along with facial displays related to joy. Still, alternative views need considering. For example, dimensional emotion models would suggest the dimension of activation as an important explanatory dimension for categorizing the 16 positive emotions. In this view, the 16 emotions could be placed along a continuum, with gratitude and contentment marking the lower end of the activation dimension and schadenfreude and amusement marking the higher end. The current data does not allow for a clear stance on whether positive emotions are best explained by categorical or dimensional description system and it remains for future studies to address this issue. Future studies should also investigate the expression of these emotions in naturalistic settings, taking into account the social context (i.e., expression when feeling unobserved vs. observed). This will help minimizing the influence of social display rules on the expression and give the opportunity to investigate differences in temporal dynamics (i.e., speed of expression start, temporal features of the smiles and laughs, etc.).

Smiling and laughter are very important nonverbal communication signals [99]. Including them in humancomputer interaction to foster more natural encounters is thus imperative (cf. Gratch et al., 2007). While various studies have been conducted on the analysis and synthesis of smiling, fewer approaches exist on the inclusion of laughter (see [100] [101] [102] [103] [104] [105]). Yet, research in this topic is growing, including large-scale interdisciplinary projects, such as the ILHAIRE project (ILHAIRE project, European Union Seventh Framework Programme (FP7/2007-2013) under Grant Agreement No. 270780, see [106] [107]).

To be able to capture naturalistic computational models of laughter, knowledge on the number and types of laughter, as well as their nonverbal expression is required. This study provides empirical evidence on the occurrence of different smiling and laughter responses for 16 enjoyable emotions, giving the finer detail to how positive emotions are expressed. Furthermore, it provides a multimodal dataset of different laughter types in a rather ecological context, which has been shown to be fruitful for automatic emotion detection (e.g., as utilized in affective computing approaches [108]). Yet, laughter stemming from other elicitors may need to be added. Coding facial action units from genuine laughter helps the synthesis of naturalistic and appropriate facial expressions in avatars, a crucial element for a successful interaction. Depending on the animation technology applied, certain virtual characters can display FACS compliant expressions.

Evidently, the knowledge transfer of this research runs both ways. Not only do AC approaches benefit from correctly detecting and producing laughter, psychology can benefit from utilizing these findings and relatively new tools, such as virtual agents and avatars in psychological research, e.g., [109] [110] [111] [112]. 


\section{ACKNOWLEDGMENT}

The research leading to these results has received funding in parts from the European Union Seventh Framework Program (FP7/2007-2013) under grant agreement $n^{\circ} 270780$ (ILHAIRE project). We would like to acknowledge the work of the Zurich Interaction and Expression Lab team (ZIEL) for their help processing the video materials.

\section{REFERENCES}

[1] Ekman, P., "Sixteen positive emotions," Emotion Researcher, vol. 18, no. 2, pp. 6-7, 2003.

[2] Ekman, P., Friesen, W.V., \& Hager, J.C., Facial Action Coding System: A technique for the measurement of facial movement, Palo Alto, CA: Consulting Psychologists Press, 2002.

[3] Darwin, C., The expression of the emotions in man and animals, UK: John Murray, 1872.

[4] Ekman, P., \& Friesen, W.V., " Felt, false and miserable smiles," Journal of Nonverbal Behavior, vol. 6, pp. 238-252, 1982: doi:10.1007/BF00987191

[5] Ruch, W., \& Ekman, P., "The expressive pattern of laughter." in Emotion, qualia, and consciousness, A.W. Kaszniak Ed. Tokyo, Japan: Word Scientific Publisher, 2001, pp. 426-443.

[6] Sauter, D.A., Eisner, F., Ekman, P., \& Scott, S.K., "Cross-cultural recognition of basic emotions through nonverbal emotional vocalizations, " Proceedings of the National Academy of Sciences, vol. 107, pp. 2408-2412, 2010: doi:10.1073/pnas.0908239106

[7] Sauter, D., McDonald, N.M., Gangi, D., \& Messinger, D.S., et al, “Nonverbal expressions of positive emotions" in Handbook of Positive Emotions, M.N. Shiota, M.M. Tugade and L.D. Kirby Eds. New York, USA: Guilford, 2013, pp. 179-199.

[8] Mortillaro, M., Mehu, M., \& Scherer, K.R., " Subtly different positive emotions can be distinguished by their facial expressions," Social Psychological and Personality Science, vol. 2, pp. 262-271, 2011: doi:10.1177/1948550610389080

[9] Ekman, P., Davidson, R.J., \& Friesen, W.V., “ The Duchenne smile: Emotional expression and brain physiology II," Journal of Personality and Social Psychology, vol. 58, pp. 342-353, 1990: doi:10.1037//0022-3514.58.2.342

[10] Mehu, M., Little, A.C., \& Dunbar, R.I., " Duchenne smiles and the perception of generosity and sociability in faces," Journal of Evolutionary Psychology, vol. 5, pp. 183-196, 2007: doi:10.1556/JEP.2007.1011

[11] Krumhuber, E.G., \& Manstead, A.S., "Can Duchenne smiles be feigned? New evidence on felt and false smiles," Emotion, vol. 9, pp. 807-820, 2009: doi:10.1037/a0017844

[12] Schmidt, K.L., Bhattacharya, S., \& Denlinger, R., “Comparison of deliberate and spontaneous facial movement in smiles and eyebrow raises," Journal of Nonverbal Behavior, vol. 33, pp. 35-45, 2009: doi:10.1007/s10919-008-0058-6

[13] Ekman, P., Friesen, W.V., \& Ancoli, S. " Facial signs of emotional experience," Journal of Personality and Social Psychology, vol. 39, pp. 1125-1134, 1980: doi:10.1037/h0077722

[14] Harris, C., \& Alvarado, N., " Facial expressions, smile types, and self-report during humor, tickle, and pain," Cognition and Emotion, vol. 19, pp. 655-669, 2005: doi:10.1080/02699930441000472

[15] Keltner, D., \& Bonanno, G.A., "A study of laughter and dissociations: Distinct correlates of laughter and smiling during bereavement," Journal of Personality and Social Psychology, vol. 73, pp. 687-702, 1997: doi:10.1037/00223514.73.4.687

[16] Keltner, D., Ekman, P., Gonzaga, G.C., \& Beer, J., Facial expression of emotion, in Handbook of affective sciences, R.J. Davidson, K.R. Scherer, and H.H. Goldsmith, Eds. London, UK: Oxford University Press, 2003, pp. 415-432.

[17] Krumhuber, E.G., Likowski, K.U., \& Weyers, P., "Facial mimicry of spontaneous and deliberate Duchenne and non-Duchenne smiles," Journal of Nonverbal Behavior, 2013: doi:10.1007/s10919-013-0167-8
[18] Mattson W.I., Cohn, J.F., Mahoor, M.H., Gangi, D.N., \& Messinger, D.S, "Darwin's Duchenne: Eye constriction during infant joy and distress," PLoS ONE, vol.8. no. 11, 2013: e80161. doi:10.1371/journal.pone.0080161

[19] Ruch, W., "Exhilaration and humor," in The Handbook of Emotions, M. Lewis and J. M. Haviland Eds. New York, USA: Guilford Publications, 1993, pp. 605-616.

[20] Scherer, K.R., \& Ceschi, G., "Criteria for emotion recognition from verbal and nonverbal expression: Studying baggage loss in the airport," Personality and Social Psychology Bulletin, vol. 26, pp. 327-339, 2000: doi:10.1177/0146167200265006

[21] Scherer, K.R., \& Ellgring, H., "Multimodal expression of emotion: Affect programs or componential appraisal patterns?," Emotion, vol. 7, pp. 158, 2007a: doi:10.1037/1528-3542.7.1.158

[22] Scherer, K.R., \& Ellgring, H., "Are facial expressions of emotion produced by categorical affect programs or dynamically driven by appraisal?" Emotion, vol. 7, pp. 113-130. 2007b: doi:10.1037/1528-3542.7.1.113

[23] Matsumoto, D., Keltner, D., Shiota, M.N., Frank, M.G., \& O'Sullivan, M., et al, "What's in a face? Facial expressions as signals of discrete emotions," in Handbook of Emotions, M. Lewis, J.M. Haviland and L. Feldman Barrett, Eds. New York, USA: Guilford Press, 2008, pp. 211-234.

[24] Platt, T., Hofmann, J., Ruch, W., \& Proyer, R.T., “Duchenne Display responses towards sixteen positive emotions: Individual differences between no and fear of being laughed at," Motivation and Emotion, vol. 37, pp. 776-786, 2013: doi10.1007/s11031-013-9342-9

[25] Ceschi, G., \& Scherer, K., " Children's ability to control the facial expression of laughter and smiling: Knowledge and behavior," Cognition and Emotion, vol. 17, pp. 385-411, 2003: doi:10.1080/02699930143000725

[26] Shiota, M.N., Campos, B., \& Keltner, D., "The faces of positive emotion," Annals of the New York Academy of Sciences, vol. 1000, pp. 296-299. 2003: doi:10.1196/annals.1280.029

[27] Ambadar, Z., Cohn, J.F., and Reed, L.I.," All smiles are not created equal Morphology and timing of smiles perceived as amused, polite, and embarrassed/nervous," Journal of Nonverbal Behavior, vol. 33, pp. 17-34, 2009: doi:10.1007/s10919-008-0059-5

[28] Schmidt, K.L., Ambadar, Z., Cohn, J.F., \& Reed, L.I., "Movement differences between deliberate and spontaneous facial expressions: Zygomaticus major action in smiling," Journal of Nonverbal Behavior, vol. 30, pp. 37-52, 2006: doi:10.1007/s10919-005-0003-x

[29] Frank, M.G., Ekman, P., \& Friesen, W.V., “ Behavioral markers and recognizability of the smile of enjoyment," Journal of Personality and Social Psychology, vol. 64, no. 1, pp. 83-93, 1993.

[30] Matsumoto, D., \& Hwang, H.C., " Judgments of subtle facial expressions of emotion," Emotion, vol.14, pp. 349-357, 2014: doi:10.1037/a0035237

[31] Mehu, M., Mortillaro, M., Bänziger, T., \& Scherer, K.R., “ Reliable facial muscles activation enhances recognisability and credibility of emotional expression," Emotion, vol. 12, pp. 701-715, 2012: doi:10.1037/a0026717

[32] Thibault, P., Gosselin, P., Brunel, M.L., \& Hess, U., “Children's and adolescents' perception of the authenticity of smiles," Journal of Experimental Child Psychology, vol. 102, no. 3, pp. 360-367. 2009: doi:10.1016/j.jecp.2008.08.005

[33] Quadflieg, S., Vermeulen, N., \& Rossion, B., "Differential reliance on the Duchenne marker during smile evaluations and person judgments," Journal of Nonverbal Behavior, vol.37, pp. 66-77, 2013: doi:10.1007/s10919-013-0147-z

[34] Keltner, D., "Signs of appeasement: Evidence for the distinct displays of embarrassment, amusement, and shame," Journal of Personality and Social Psychology, vol. 68, pp. 441-454, 1995: doi:10.1037//0022-3514.68.3.441

[35] Campos, B., Shiota, M.N., Keltner, D., Gonzaga, G.C., \& Goetz, J.L., "What is shared, what is different? Core relational themes and expressive displays of eight positive emotions," Cognition and Emotion, vo. 27, pp. 37-52, 2013: doi:10.1080/02699931.2012.683852

[36] Ruch, W., Hofmann, J., \& Platt, T., "Investigating facial features of four types of laughter in historic illustrations," European Journal of Humor Research, vol. 1 , no. 1, pp. 98-118, 2013.

[37] Hofmann, J., " Intense or malicious? The decoding of eyebrow-lowering frowning in laughter animations depends on the presentation mode," Frontiers in Psychology, vol. 5, no. 1306, 2014: doi:10.3389/fpsyg.2014.01306 
[38] Szameitat, D.P., Alter, K., Szameitat, A.J., Wildgruber, D., Sterr, A., \& Darwin, C.J., "Acoustic profiles of distinct emotional expressions in laughter," Journal of the Acoustical Society of America, vol. 126, pp. 354-366, 2009: doi:10.1121/1.3139899

[39] Cikara, M., \& Fiske, S.T., “ Their pain, our pleasure: stereotype content and schadenfreude," Annals of the New York Academy of Sciences, vol. 1299, no. 1, pp. 52-59, 2013

[40] Pietraszkiewicz, A., "Schadenfreude and just world belief," Australian Journal of Psychology, vol. 65, pp. 188-194, 2013: doi:10.1111/ajpy.12020

[41] Sauter, D.A., \& Scott, S.K., "More than one kind of happiness: Can we recognize vocal expressions of different positive states?," Motivation and Emotion, vol. 31, pp. 192-199, 2006: doi:10.1007/s11031-007-9065-x

[42] Fogel, A., Nelson-Goens, G.C., \& Hsu, H.C., “ Do different infant smiles reflect different positive emotions?", Social Development, vol. 9, pp. 497-520, 2001: doi:10.1111/1467-9507.00140

[43] Rothbart, M., "Laughter in young children," Psychological Bulletin, vol. 80, pp. 247- 256, 1973: doi:10.1037/h0034846

[44] Frijda, N.H., The emotions, Cambridge, UK: Cambridge University Press, 1986

[45] Krumhuber, E.G., \& Scherer, K. "Affect bursts: Dynamic patterns of facial expression," Emotion, vol. 4, pp.825-841, 2011: doi:10.1037/a0023856

[46] Ikeda, A., \& Itakura, S., "Influence of maternal social communication on ticklishness in infants: A comparison with being stroked," Infancy, vol. 18, pp. 69-80, 2013: doi:10.1111/infa.12029

[47] Panksepp, J., \& Burgdorf, J., “"'Laughing" rats and the evolutionary antecedents of human joy?," Physiology Behavior, vol. 79, pp. 533-547, 2003: doi:10.1016/S0031-9384(03)00159-8

[48] Kaye, A., Kaye, A., Swinford, J., Baluch, A., Bawcom, B., Lambert, T., \& Hoover, J., " The effect of deep-tissue massage therapy on blood pressure and heart rate," Journal of Alternative and Complementary Medicine, vol. 14, pp. 125128, 2008: doi:10.1089/acm.2007.0665

[49] Matsumoto, D., \& Willingham, B., "Spontaneous facial expressions of emotion of congenitally and non-congenitally blind individuals," Journal of Personality and Social Psychology, vol. 96, pp. 1-10, 2009: doi:10.1037/a0014037

[50] Hawk, S.T., Van Kleef, G.A., Fischer, A.H., \& Van der Schalk, J., " "Worth a thousand words": Absolute and relative decoding of nonlinguistic affect vocalizations," Emotion, vol. 9, pp. 293-305, 2009: doi:10.1037/a0015178

[51] Tracy, J.L., \& Matsumoto, D., “The spontaneous expression of pride and shame: Evidence for biologically innate nonverbal displays" Proceedings of the National Academy of Sciences, vol. 105, pp. 11655-11660. 2008: doi:10.1073/pnas.0802686105

[52] Tracy, J.L., \& Robins, R. W., “The prototypical pride expression: Development of a nonverbal behavior coding system," Emotion, vol. 7, pp. 789-801, 2007: doi:10.1037/1528-3542.7.4.789

[53] Haviland-Jones, J., Rosario, H.H., Wilson, P., \& McGuire, T.R., “An environmental approach to positive emotion: Flowers," Evolutionary Psychology, vol. 3, pp. 104-132, 2005.

[54] Dumas, G., La vie affective, Paris, France: Presses Universitaires de France, 1948.

[55] Fredrickson, B.L., \& Branigan, C.," Positive emotions," in Emotion: Current issues and future directions, T.J. Mayne and G.A. Bonnano, Eds. New York, USA: Guilford Press, 2001, pp. 123-151.

[56] Elfenbein, H.A., Beaupré, M., Lévesque, M., \& Hess, U., “ Toward a dialect theory: cultural differences in the expression and recognition of posed facial expressions," Emotion, vol. 7, pp. 131-146, 2007: doi:10.1037/1528-3542.7.1.131

[57] McCullough, M.E., Kilpatrick, S.D., Emmons, R.A., \& Larson, D.B., “ Is gratitude a moral affect?," Psychological Bulletin, vol. 127, pp. 249-266, 2001: doi:10.1037//0033-2909.127.2.249

[58] Duchenne, B., The mechanism of human facial expression, R.A. Cuthbertson, Ed. and Trans., Cambridge, UK: Cambridge University Press., 1862/1990.

[59] Algoe, S.B., \& Haidt, J., “Witnessing excellence in action: The 'other-praising' emotions of elevation, gratitude, and admiration," The Journal of Positive Psychology, vol. 4, no. 2, pp. 105-127, 2009.

[60] Cowie, R., Douglas-Cowie, E., Tsapatsoulis, N., Votsis, G., Kollias, S., Fellenz, W., \& Taylor, J.G., " Emotion recognition in human-computer interaction," Signal Processing Magazine, IEEE, vol. 18, no. 1, pp. 32-80, 2001.
[61] Plutchik, R., Emotion: A psycho-evolutionary synthesis, New York, USA: Harper \& Row, 1980

[62] Russell, J.A., "A circumplex model of affect," Journal of Personality and Social Psychology, vol. 39, pp. 1161-1178, 1980: doi: 10.1037/h0077714

[63] Sayette, M.A., Cohn, J.F., Wertz, J.M., Perrott, M.A., \& Parrott, D.J., “A psychometric evaluation of the facial action coding system for assessing spontaneous expression," Journal of Nonverbal Behavior, vol. 25, no.3, pp. 167-185, 2001.

[64] Porter, S., Bhanwer, A., Woodworth, M., \& Black, P. J., “Soldiers of misfortune: An examination of the Dark Triad and the experience of schadenfreude," Personality and Individual Differences, 2013: Advance online publication. doi:10.1016/j.paid.2013.11.014

[65] Herring, D.R., Burleson, M.H., Roberts, N.A., \& Devine, M.J., " Coherent with laughter: Subjective experience, behavior, and physiological responses during amusement and joy," International Journal of Psychophysiology, vol. 79, pp. 211218, 2011: doi:10.1016/j.jpsycho.2010.10.007

[66] Bänziger, T., Mortillaro, M., \& Scherer, K.R. “ Introducing the Geneva Multimodal Expression Corpus for experimental research on emotion perception," Emotion, vol.12, pp. 1161-1179, 2012: doi:10.1037/a0025827

[67] Wiggers, M., “Judgment of facial expressions of emotion predicted from facial behavior," Journal of Nonverbal Behavior, vol. 7, pp. 101-116, 1982: doi:10.1007/BF00986872

[68] Wehrle, T., Kaiser, S., Schmidt, S., \& Scherer, K.R., "Studying the dynamics of emotional expression using synthesized facial muscle movements," Journal of Personality and Social Psychology, vol. 78, pp. 105-119, 2000: doi:10.1037/00223514.78.1.105

[69] Fogel, A., Toda, S., \& Kawai, M., “ Mother-infant face-to-face interaction in Japan and the United States: A laboratory comparison using 3-month-old infants," Developmental Psychology, vol. 24, pp. 398-406, 1988, doi:10.1037/0012-1649.24.3.398

[70] Sneddon, I., McKeown, G., McRorie, M., \& Vukicevic, T., “Cross-cultural patterns in dynamic ratings of positive and negative natural emotional behavior," PLoS ONE, vol. 6 no. 2, 2011: doi:10.1371/journal.pone.0014679

[71] Tsai, J.L., "Ideal affect: Cultural causes and behavioral consequences" Perspectives on Psychological Science, vol. 2, no. 3, pp. 242-259, 2007.

[72] Elfenbein, H.A., \& Ambady, N., “On the universality and cultural specificity of emotion recognition: A meta-analysis," Psychological Bulletin, vol. 128, pp. 203-235, 2002: doi:10.1037//0033-2909.128.2.203

[73] Juslin, P.N., \& Laukka, P., “ Communication of emotions in vocal expression and music performance: Different channels, same code?" Psychological Bulletin, vol. 129, pp. 770-814, 2003: doi:10.1037/0033-2909.129.5.770

[74] Laukka, P., Elfenbein, H.A., Söder, N., Nordström, H., Althoff, J., Chui, W., et al., " Cross-cultural decoding of positive and negative nonlinguistic emotion vocalizations," Frontiers in Psychology, vol. 4, 2013: doi:10.3389/fpsyg.2013.00353

[75] Patel, S., Scherer, K.R., Björkner, E., \& Sundberg, J., “Mapping emotions into acoustic space: The role of voice production, "Biological Psychology, vol. 65, pp. 188-194, 2011: doi:10.1016/j.biopsycho.2011.02.010

[76] Simon-Thomas, E.R., Keltner, D.J., Sauter, D., Sinicropi-Yao, L., \& Abramson, A., "The voice conveys specific emotions: evidence from vocal burst displays, "Emotion, vol. 9, pp. 838-846, 2009: doi:10.1037/a0017810

[77] App, B., McIntosh, D.N., Reed, C.L., \& Hertenstein, M.J., “ Nonverbal channel use in communication of emotion," Emotion, vol.11, pp. 603-617, 2011: doi:10.1037/a0023164

[78] Hertenstein, M.J., Keltner, D., App, B., Bulleit, B.A., \& Jaskolka, A.R., “ Touch communicates distinct emotions," Emotion, vol. 6, pp. 528-533, 2006, doi:10.1037/1528-3542.6.3.528

[79] Bloch, S., Orthous, P., \& Santibañez-H, G. “ Effector patterns of basic emotions: A psychophysiological method for training actors," Journal of Social and Biological Structures, vol. 10, pp.1-19, 1987: doi:10.1016/01401750(87)90031-5

[80] Hatfield, E., \& Rapson, R.L., "Love and attachment process," in The handbook of emotions, 2nd ed, M. Lewis and J.M. Haviland, Eds. New York, USA: Guilford Publications, 2000, pp. 645-663. 
[81] Kalawski, J.P.," Is tenderness a basic emotion?," Motivation and Emotion, vol. 34, pp. 158-167, 2010: doi:10.1007/s11031-010-9164-y

[82] Sabini, J., \& Silver, M., "Ekman's basic emotions: Why not love and jealousy?" Cognition and Emotion, vol. 19, pp. 693-712, 2005: doi:10.1080/02699930441000481

[83] Shaver, P.R., Morgan, H.J., \& Wu, S., "Is love a "basic" emotion? Personal Relationships," vol. 3, no. 1, pp. 81-96, 1996.

[84] Izard, C.E., " Basic emotions, relations among emotions, and emotioncognition relations," Psychological Review, vol. 99, pp. 561-565, 1992: doi:10.1037/0033-295X.99.3.561

[85] Fredrickson, B.L., "What good are positive emotions?," Review of General Psychology, vol. 2, pp. 300-319, 1998: doi:10.1037//1089-2680.2.3.300

[86] Gonzaga, G.C., Keltner, D., Londahl, E.A., \& Smith, M.D., “ Love and the commitment problem in romantic relations and friendship," Journal of Personality and Social Psychology, vol. 81, pp. 247-262, 2001: doi:10.1037//00223514.81.2.247

[87] Reeve, J., \& Nix, G., "Expressing intrinsic motivation through acts of exploration and facial displays of interest," Motivation and Emotion, vol. 21, no. 3, pp. 237-250, 1997

[88] Bonanno, G.A., \& Keltner, D., “ The coherence of emotion systems: Comparing 'on-line' measures of appraisal and facial expressions, and selfreport," Cognition and Emotion, vol. 18, pp. 431-444, 2004: doi:10.1080/02699931.2012.683852

[89] Verduyn, P., van Mechelen, I., Tuerlinckx, F., Meers, K., \& van Coillie, H., "Intensity profiles of emotional experience over time," Cognition and Emotion, vol. 23, pp. 1427-1443, 2009: doi:10.1080/02699930902949031

[90] Scherer, K.R., "Vocal affect signaling: A comparative approach," in Advances in the study of behavior, vol. 15, J. Rosenblatt, C. Beer, M.C. Busnel, \& P.J.B. Slater, Eds. New York, USA: Academic Press, 1985, pp. 189-244.

[91] Laukka, P., Juslin, P., \& Bresin, R., “A dimensional approach to vocal expression of emotion," Cognition \& Emotion, vol. 19, pp. 633-653, 2005: doi:10.1080/02699930441000445

[92] Ortony, A., \& Turner, T. J., ,,What's basic about basic emotions?" Psychological Review, vol.97, pp. 315-331, 1990: doi:10.1037/0033-295X.97.3.315

[93] Ekman, P., Friesen, W.V., \& Ellsworth, P., „Conceptual ambiguities“ In Emotions in the human face, Ekman, P., ed., Cambridge, Cambridge University Press.

[94] Van Hooff, J. A. R. A. M., ,,A comparative approach to the phylogeny of laughter and smiling." In Non-verbal communication, R. A. Hinde, Ed., Cambridge, UK: Cambridge University Press, pp. 209-240, 1972.

[95] Coan, J. A., \& Allen, J. J., Handbook of emotion elicitation and assessment. Oxford: Oxford University Press, 2007.

[96] Dibeklioglu, H., Salah, A.A. \& Gevers, T. „,Recognition of genuine smiles.“, IEEE Transactions on Multimedia, vol. 17(3), pp.279-294, 2009.

[97] Dibeklioglu, H., Alnajar, F., Salah, A.A. \& Gevers, T. „Combining facial dynamics with appearance for age estimation", IEEE Transactions on Image Processing", vol. 24(6), pp.1928-1943, 2015.

[98] Valstar, M.F., Gunes, H. \& Pantic, M., „How to distinguish posed from spontaneous smiles using geometric features", In Proceedings of the 9th International Conference on Multimodal Interfaces , 2007, (pp. 38-45). ACM.

[99] Hofmann, J., \& Ruch, W., „Laughter". In Oxford Bibliographies Online. D. S. Dunn, ed., New York: Oxford University Press. Article accepted for publication 23.12.2016. www.oxfordbibliographies.com

[100] Batliner, A., Steidl, S., Eyben, F., \& Schuller, B. On laughter and speech laugh, based on observations of child-robot interaction. In The phonetics of laughing, J. Trouvain \& N. Campbell, Eds.,. Saarbrücken, Germany: Saarland University Press, 2011.

[101] Becker-Asano, C., Kanda, T., Ishi, C., \& Ishiguro, H. „How about laughter? Perceived naturalness of two laughing humanoid robots" ${ }^{\prime \prime}$ Paper presented at the Affective Computing and Intelligent Interaction ACII3 (pp.1-6). Amsterdam, Netherlands, 2009: doi:10.1109/acii.2009.5349371

[102] Bonin, F., Campbell, N., \& Vogel, C. “Time for laughter." Knowledge-Based Systems, 2014. doi:10.1016/j.knosys.2014.04.031v
[103] Pelachaud, C., “Modeling multimodal expression of emotion in a virtual agent", Philosophical Transactions of the Royal Society B: Biological Sciences, vol. 364(1535), pp. 3539-3548, 2009.

[104] Ruch, W., Platt, T., Hofmann, J., Niewiadomski, R., Urbain, J., Mancini, M., \& Dupont, S., "Gelotophobia and the challenges of implementing laughter into Virtual Agents interactions" Frontiers in Human Neuroscience, 8:928, 2014: doi: 10.3389/fnhum.2014.00928

[105] Urbain, J., Niewiadomski, R., Bevaqua, E., Dutoit, T., Moinet, A., et al., “AV Laughter Cycle" Journal on Multimodal User Interfaces, vol. 4, pp. 47-58, 2009: doi:10.1007/s12193-010-0053-1

[106] Dupont, S. Cakmak, H., Curran, W., Dutoit, Th., Hofmann, J., McKeown, G., Pietiquin, O., Platt, T., Ruch, W., \& Urbain, J. “'Laughter Research: a Review of the ILHAIRE Project". In A. Esposito and L. C. Chain, Eds., Toward Robotic Socially Believable Behaving Systems - Volume I - Modelling Emotions (pp. 147-181). New York, USA:Springer, 2016: doi: 10.1007/978-3-319-31056-5_9

[107] Niewiadomski, R., Urbain, J., Pelachaud, C., \& Dutoit, T., “Finding out the audio and visual features that influence the perception of laughter intensity and differ in inhalation and exhalation phases", In Proceedings of 4th International Workshop on Corpora for Research on Emotion, Sentiment \& Social Signals, LREC 2012 (pp. 25-32). Istanbul, Turkey, 2012.

[108] Cowie, R., Douglas-Cowie, E., Tsapatsoulis, N., Votsis, G., Kollias, S., Fellenz, W., \& Taylor, J. G., "Emotion recognition in human-computer interaction". Signal Processing Magazine, IEEE, vol. 18(1), pp. 32-80, 2001.

[109] Blascovich, J., Loomis, J., Beall, A. C., Swinth, K. R., Hoyt, C. L., \& Bailenson, J. $\mathrm{N}$., "Immersive virtual environment technology as a methodological tool for social psychology", Psychological Inquiry, vol.13, pp. 103-124, 2002.

[110] Fox, J., Arena, D., \& Bailenson, J. N. “Virtual reality: A survival guide for the social scientist", Journal of Media Psychology: Theories, Methods, and Applications, vol. 21(3), pp. 95-103, 2009.

[111] Boker, S. M., Cohn, J. F., Theobald, B. J., Matthews, I., Brick, T. R., \& Spies, J. R., "Effects of damping head movement and facial expression in dyadic conversation using real-time facial expression tracking and synthesized avatars", Philosophical Transactions of the Royal Society B: Biological Sciences, vol. 364, pp. 3485-3495, 2009: doi:10.1098/rstb.2009.0152

[112] Pantic, M., Cowie, R., D'Errico, F., Heylen, D., Mehu, M., Pelachaud, C., et al., "Social signal processing: The research agenda." In Visual analysis of humans (pp. 511-538), 2011. London, UK: Springer.

[113] Ruch, W., \& Hofmann, J. “Psychologie, Medizin, Hirnforschung. [Humor in Psychology, Medicine, and Brain Research]" In U. Wirth (Ed.), Handbuch der Komik [Handbook of the comic] (pp. 89-101). Stuttgart, Germany: J. B. Metzler, 2017. doi: 10.1007/978-3-476-05391-6_16 
Jennifer Hofmann $\mathrm{PhD}$ is a senior teaching and research fellow at the department of personality and assessment (Institute of Psychology), University of Zurich. She completed her PhD in the same department prior to which she studied psychology, psychopathology in adulthood and social pedagogy. As a doctorate from 2010 to 2014 she worked for the Institute of Psychology, University of Zurich and the Distance Learning University, Brig (Switzerland). She has written over 30 journal articles, book chapters and encyclopedia entries. She was awarded the DANYS award from the International Society for Humor Studies as the emerging scholar of 2014 and has been involved in the FET OPEN ILHAIRE (www.ilhaire.eu) project, as well as several national grants. Her current research interests are in personality and assessment, en-and decoding of positive emotions, humor, as well as nonverbal behavior (applying the Facial Action Coding System).

Tracey Platt PhD is a Senior lecturer in the Institute of Psychology at the university of Wolverhampton, UK. She received a Master of Science (M.Sc.) in Work and Organisational Psychology in the UK and completed her PhD at the Department of Personality and Assessment, University of Zurich in 2013, where she also worked as an assistant researcher from 2009 to 2014. She has 39 peer review journal articles, book chapters and encyclopedia entries. She was the 2011 Humour Society's Graduate Student Emerging Scholar award. She has been involved in the FET OPEN ILHAIRE (www.ilhaire.eu) project, as well as several national grants. Her research interest is in positive social interactions, with a focus on non-verbal behavior, positive emotions and utilizing the Facial Action Coding System.

Willibald Ruch PhD is a full professor at the department of personality and assessment (Institute of Psychology), University of Zurich. Studied at the Karl-Franzens-University of Graz (Department of Psychology, Director: Prof. Dr. Erich Mittenecker) and Miami University, Oxford, OH, USA. He received his PhD (Dr. phil.) in 1980: At the Faculty of Science of the University of Graz. In 1991 he gained his Habilitation at the Math.Nat. Faculty of Heinrich-Heine University in Dusseldorf, Fellow at the German Research Foundation DFG Heisenberg Programme, apl Professor Math.Nat. faculty of Heinrich Heine University of Dusseldorf. After which time he became a Senior Lecturer for individual differences / motivation \& emotion, at the School of Psychology, Queen's University of Belfast, Belfast, UK. Since 2002 he has been the chair of Personality and Assessment in the Department of Psychology, University of Zurich. He has authored and co-authored over 200 journal articles and 5 books: The sense of humor: Explorations of a personality characteristic (Humor Research Series, Vol. 3); Ostendorf, F., Angleitner, A., \& Ruch, W. (1986). Die Multitrait- Multimethod Analyse. Konvergente und diskriminante Validität der Personality Research Form [Multitrait-Multimethod Analysis: The Convergent and Discriminant Validity of the Personality Research Form; Hehl, F.-J., Ebel, V., \& Ruch, W. (1985) (Eds.). Diagnostik und Evaluation bei betrieblichen, politischen und juristischen Entscheidungen [The Diagnostics and Evaluation of Corporate, Political, and Legal Decisions]; Hehl, F.-J., Ebel, V., \& Ruch, W. (1985). (Eds.). Diagnostik psychischer und psychophysiologischer Störungen [The Diagnostics of Psychic and Psychophysiological Disorders]; Hehl, F.-J., Ebel, V., \& Ruch, W. (1985). (Eds.). Psychologische Diagnostik. Kinder, Familie, Schule, Sport. [Psychological Diagnostics: Children, Family, School, Sports]. He is on the editorial board of Eleven journals, and is a Fellow of International Positive Psychology Association, the president of the Swiss Association for Positive Psychology and past president of the International Society for Humor Studies. 